7th International Symposium on Superalloy 718 and Derivatives

Edited by: E.A. Ott, J.R. Groh, A. Banik, I. Dempster, T.P. Gabb, R. Helmink, X. Liu, A. Mitchell, G.P. Sjöberg, and A. Wusatowska-Sarnek

TMS (The Minerals, Metals \& Materials Society), 2010

\title{
Investigation of Homogenization and its Influence on the Repair Welding of Cast Allvac 718Plus
}

\author{
Joel Andersson ${ }^{1,2}$, Göran Sjöberg ${ }^{1,2}$, Josefin Larsson ${ }^{2}$ \\ ${ }^{1}$ Volvo Aero Corporation \\ Materials Technology Department, Trollhättan, 461 81, Sweden \\ ${ }^{2}$ Chalmers University of Technology, Department of Materials and Manufacturing Technology, \\ Göteborg, 412 96, Sweden
}

Keywords: Allvac 718Plus, casting, homogenization, welding

\begin{abstract}
Heat treatment experiments have been carried out to bring understanding to the efficacy of different temperatures and dwell times on the degree of homogenization of the cast Allvac 718 Plus alloy which is prone to segregation mainly due to its high content of niobium. The effect of homogenization on weld repair was also examined. The homogenization heat treatment temperatures ranged from $1050^{\circ} \mathrm{C}$ to $1200^{\circ} \mathrm{C}$ with $1 \mathrm{hr}, 5 \mathrm{hrs}$ and $10 \mathrm{hrs}$ dwell times. The degree of homogenization was measured as the reduction of the amount of Laves phase by manual point counting in an optical microscope at high magnification. Longer range, interdendritic, patterns were established through line scan EDS analysis in SEM. It was found that short time (1hr) does not significantly reduce the amount of Laves phase whereas $5 \mathrm{hrs}$ and $10 \mathrm{hrs}$ are much more efficient. Interdendritic homogenization does not occur to any measurable extent even at the highest temperature and longest dwell time $\left(1200^{\circ} \mathrm{C}-10 \mathrm{hrs}\right)$ which was also reflected in bulk macro Vickers hardness tests.
\end{abstract}

In the weld repair tests, one of the most homogenized material conditions $\left(1125^{\circ} \mathrm{C}-5 \mathrm{hrs}\right.$ $+1200^{\circ} \mathrm{C}-10 \mathrm{hrs}$ ) turned out to be the most prone to cracking while the number of weld cracks after a moderate homogenization heat treatment $\left(1125^{\circ} \mathrm{C}-5 \mathrm{hrs}\right)$ was much smaller .

\section{Introduction}

The research and developments efforts behind the Alloy 718 were at the very early stage focused on the wrought material form. The benefits of the material as cast and the importance of the casting process of this alloy were only later realized. The cast form differs considerably from the material as wrought including having a lower strength. This is mainly due to the solidification process and the segregation of the various elements where homogenization generally is considered as very beneficial. The homogenization of Alloy 718 has consequently been studied [1] but several issues are still unsettled.

Welding of cast Alloy 718 is a very important manufacturing process including needing a repair procedure on casting, and, without which, large castings could not be produced. In addition, for optimized design purposes, cast parts are often joined with the same wrought material by welding [2]. In all, cast material is more difficult to weld than the material as wrought which relates to the inhomogeneous nature of the casting which stresses the importance of fundamentally understanding the effect of homogenization. 
The development of the more temperature capable Allvac 718Plus has followed the same path as Alloy 718 [3] although the chemistry of the cast version of Allvac 718Plus alloy is not yet firmly established and therefore the subject of a second MAI (Material Affordable Initiative) project in the USA. Thus the wrought composition of the bar stock material used in the present study should be considered as only indicative, as our results presented, on what may be achieved with the finally established composition.

The Allvac 718Plus alloy is primarily considered as a $\gamma^{\prime}$ hardened alloy while Alloy 718 is hardened by $\gamma$ ' precipitates. Still, Allvac 718Plus has, as Alloy 718, a favorable slow hardening response which adds to the weldability. The chemistries of these two alloys have compositional similarities as evident from Table 1 and it is not surprising to find the weldability of the wrought material at par [3].

Table 1. Nominal chemical composition of Waspaloy, Alloy 718 and Allvac 718Plus.

\begin{tabular}{ccccccccccccc}
\hline \multicolumn{2}{c}{ Alloy/Element Ni } & $\mathbf{F e}$ & $\mathbf{C r}$ & $\mathbf{C o}$ & $\mathbf{M o}$ & $\mathbf{N b}$ & $\mathbf{T i}$ & $\mathbf{A l}$ & $\mathbf{W}$ & $\mathbf{C}$ & $\mathbf{P}$ & $\mathbf{B}$ \\
\hline Waspaloy & Bal. & - & 19.4 & 13,3 & 4.3 & - & 3.0 & 1.30 & - & 0.035 & 0.006 & 0.006 \\
Alloy 718 & Bal. & 18.0 & 18.1 & - & 2.9 & 5.40 & 1.0 & 0.45 & - & 0.025 & 0.007 & 0.004 \\
Allvac 718Plus & Bal. & 10.0 & 18.0 & 9.0 & 2.8 & 5.45 & 0.7 & 1.45 & 1.0 & 0.025 & 0.014 & 0.006 \\
\hline
\end{tabular}

When welding wrought material a solution heat treatment is normally performed both before the welding to reduce the risk of cracking by keeping the material in the softest possible condition and after the welding for the purpose of stress relief, dissolving the hardening precipitates, primarily $\gamma^{\prime}$ and $\gamma^{\prime}$, and to precipitate the orthorhombic Delta phase at the grain boundaries [1, 4]. The solution temperature of Delta phase in Allvac 718 Plus is $\sim 1010^{\circ} \mathrm{C}$ above which grain coarsening will take place in the wrought material [4]. It is a general assumption that a material with coarse grains is less weldable than one with finer [5]. However, the influence of Delta phase on weldability is not fully understood. Delta phase at the grain boundaries is believed to reduce the on-heating ductility since it may promote constitutional liquation wetting the grain boundaries which will lose their strength. Still even if ductility drops as a result of the liquation the amount of eutectic liquid is increased and potentially raises the ability for backfilling that is to heal cracks [6].

Welding cast materials usually involves the same type of heat treatments as for wrought when the component is in the homogenized state although the solution temperature may however be considerably higher since there is no risk for grain growth as in the wrought material. Before welding, homogenization heat treatments are usually carried out on casting but temperatures and dwell times vary among manufacturers. Today there is no standard procedure for the Allvac 718Plus cast superalloy but similarities with Alloy 718 advocate the same heat treatment schedules as a starting point.

In both Alloy 718 and Allvac 718Plus the key element to pay attention to during the homogenization heat treatment is $\mathrm{Nb}$ since it is the main constituent in two eutectic reactions, the MC and Laves eutectics, as shown for Allvac 718Plus in the DSC analysis in Figure 1 [3]. 


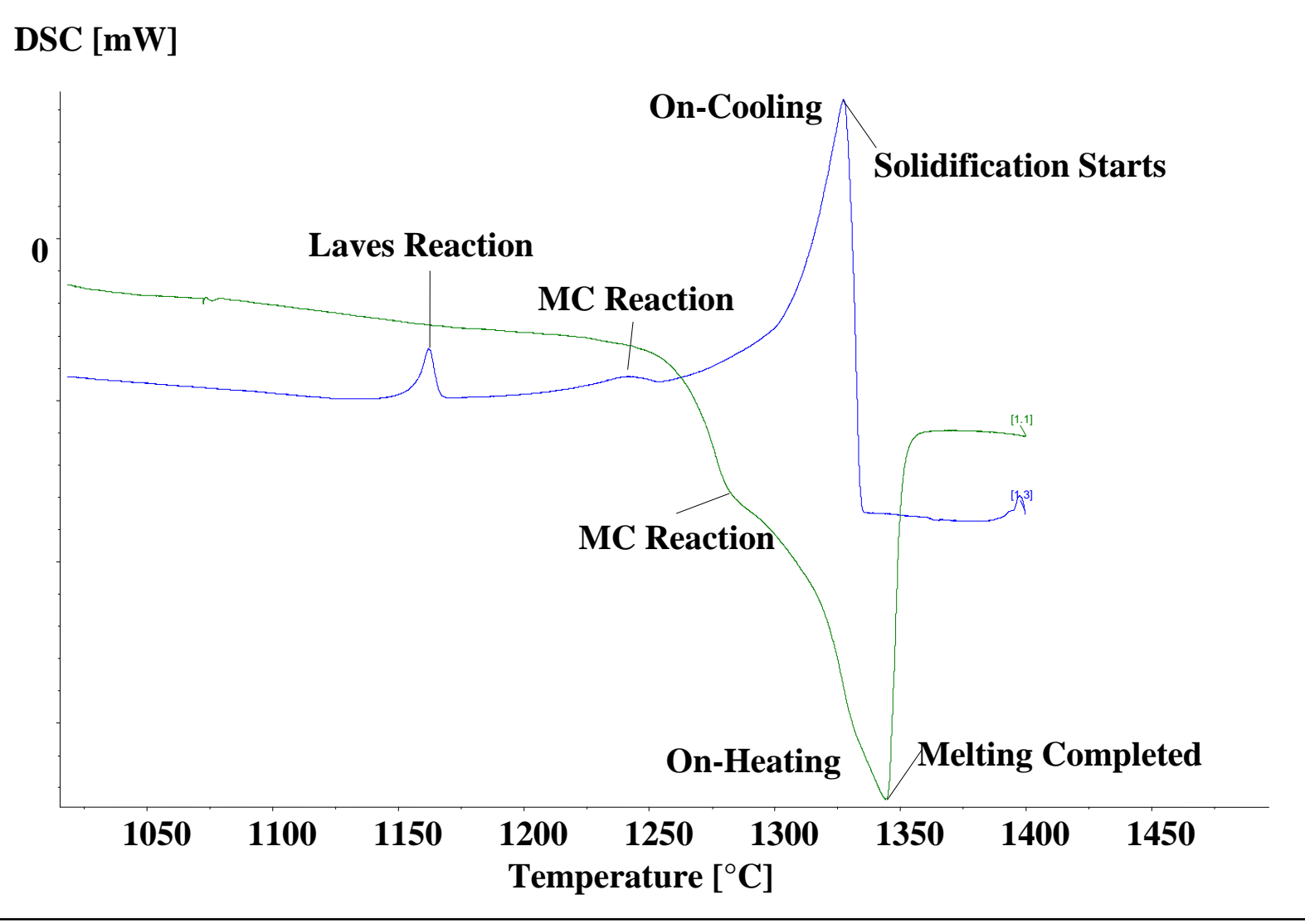

Figure 1. Heating and solidification sequence of Allvac 718Plus wrought superalloy using heating and cooling rates of $20^{\circ} \mathrm{C} / \mathrm{min}$, respectively [3].

The thermal analysis in Figure 1 is performed on wrought Allvac 718Plus but the on-cooling, solidification, part of the curve can still be used as guideline when heat treating cast material since the fundamental metallurgical reactions on the cooling will not differ. It is clearly seen that the solidification begins at around $1350^{\circ} \mathrm{C}$ followed by a $\mathrm{MC}$ eutectic reaction at $\sim 1260^{\circ} \mathrm{C}$ and terminates at $\sim 1170^{\circ} \mathrm{C}$ with the Laves eutectic reaction. Since the Laves phase contains a large amount of $\mathrm{Nb}$ (roughly $\sim 35 \mathrm{wt} \% \mathrm{Nb}$ in Laves and $8-20 \mathrm{wt} \% \mathrm{Nb}$ in $\gamma+$ Laves eutectic) this is the important temperature regime to look into when homogenization of cast Allvac 718Plus is to be performed.

\section{Experimental}

Staircase test pieces of Allvac 718Plus were cast to investigate the homogenization and repair weldability on different thicknesses associated with variation of grain size and segregation patterns. X-ray inspection and fluorescent penetrant inspection were performed on all test blanks. Although welding is affected primarily by the chemical composition and the segregation patterns (the main issues for the present study) the geometrical constraints during the welding process are important in causing excessive strains. The thickest staircase step $(15 \mathrm{~mm})$ represents a worst case scenario in combining the most severe segregation pattern and at the same time the largest constraint. The large micro-structural differences are clearly seen in the etched slice in Figure 2. The etching was performed in ferric chloride after thorough cleaning in an alkali solution. A short $(15 \mathrm{sec}$.) final nitric-hydrochloric etch was used to remove smut. 

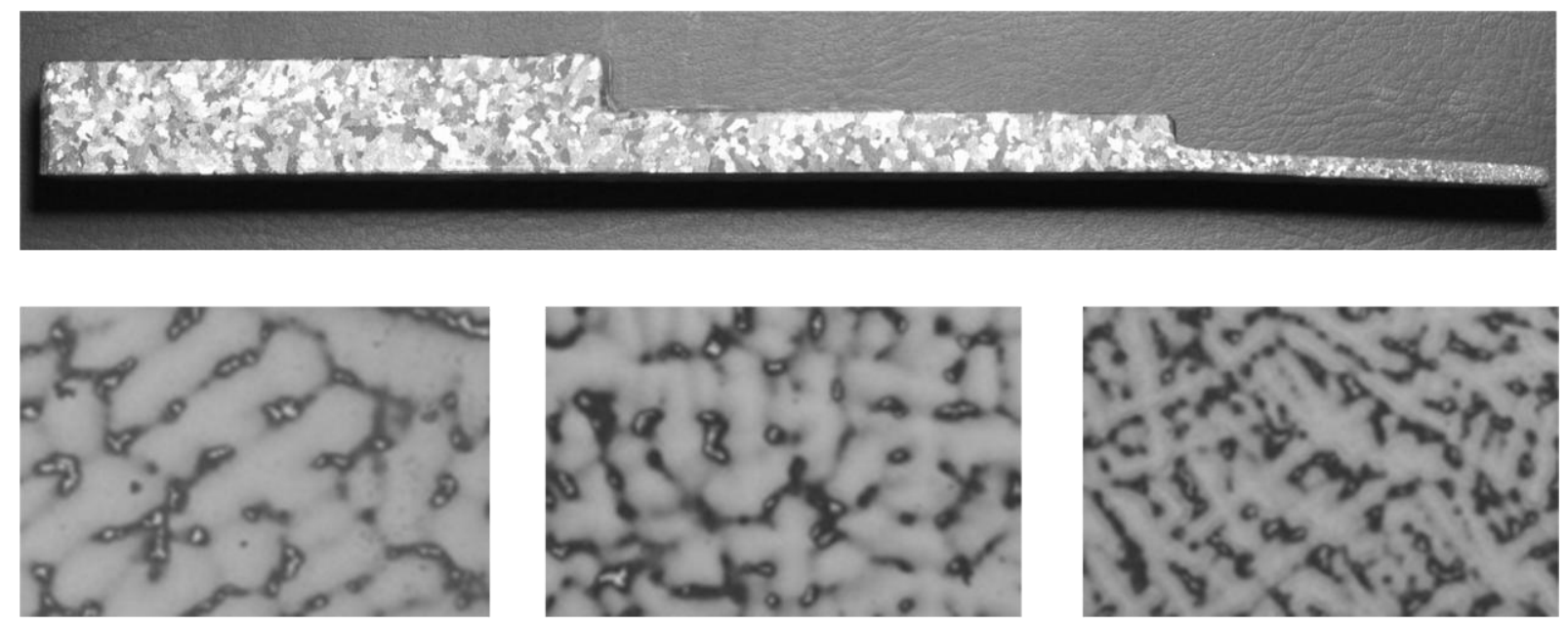

$0.5 \mathrm{~mm}$

Figure 2. A macro etched crossection of $200 \times 200 \mathrm{~mm}$ cast staircase shaped test blank with three different thicknessess $(15,10$ and $5 \mathrm{~mm})$ of Allvac 718Plus together with micrographs from each section (from separate metallographic preparations).

The homogenization heat treatment experiments were carried out on small, cut out, specimens ( typically 5 by 5 by $5 \mathrm{~mm}$ ) in a fast responding laboratory furnace at temperatures between $1050^{\circ} \mathrm{C}$ to $1200^{\circ} \mathrm{C}$ in steps of $25^{\circ} \mathrm{C}$ and for $1 \mathrm{hr}$, 5hrs and $10 \mathrm{hrs}$ at all selected temperatures - in total 21 different heat treatments. Two pieces were heat treated at the same time, one of which was subsequently age-hardened at $788^{\circ} \mathrm{C}$ for $8 \mathrm{hrs}$. Metallographic preparations of samples were carried out by standard metallographic procedures using electrolytic etching with $10 \%$ oxalic acid at 4 to $9 \mathrm{~V}$.

Since the deleterious, brittle Laves phase is not a sTable one, but precipitated as a constituent of the eutectic reaction at $1170^{\circ} \mathrm{C}$, mentioned above, and only due to segregation effects; it may also be dissolved in the solid state below the eutectic temperature as a result of a homogenization heat treatment if given enough time at the high temperatures. The amount of the remaining Laves phase can then be used as an indicator of the degree of homogenization.

Quantitative measurements of Laves phase was done with the manual grid point counting method in accordance with the standard procedures of ASTM E562-08. The measurement was made on both test specimens (as homogenized and with the subsequent aging) from each heat treatment and the average value, of the total 1872 counts sum, were used since it was assumed that the aging heat treatment will not alter the amount of Laves phase due to the comparatively low temperature at which this heat treatment is carried out.

To study the effect of homogenization on the variation of the chemical composition over the secondary dendritic arm spacings, a standard EDS line scanning procedure in SEM was used in the BSD mode at $20 \mathrm{kV}$ and results evaluated with the LINK ISIS software. The elements of interest were $\mathrm{Nb}, \mathrm{Al}, \mathrm{Ti}, \mathrm{Cr}, \mathrm{Co}$ and $\mathrm{Fe}$. The device was calibrated against a Co reference sample once every hour.

Since homogenization can be expected to improve the average effect of the hardening elements (mainly $\mathrm{Nb}, \mathrm{Al}$ and $\mathrm{Ti}$ ) macro Vickers hardness measurements were carried out on all hardened heat treated samples. 
The stair case test pieces chosen for weld trials were first heat treated in a vacuum furnace followed by machining grooves for the weld repair as indicated in Figure 3. The repair trials were then performed using gas tungsten arc welding with argon as shielding gas and Allvac 718 Plus as filler material.

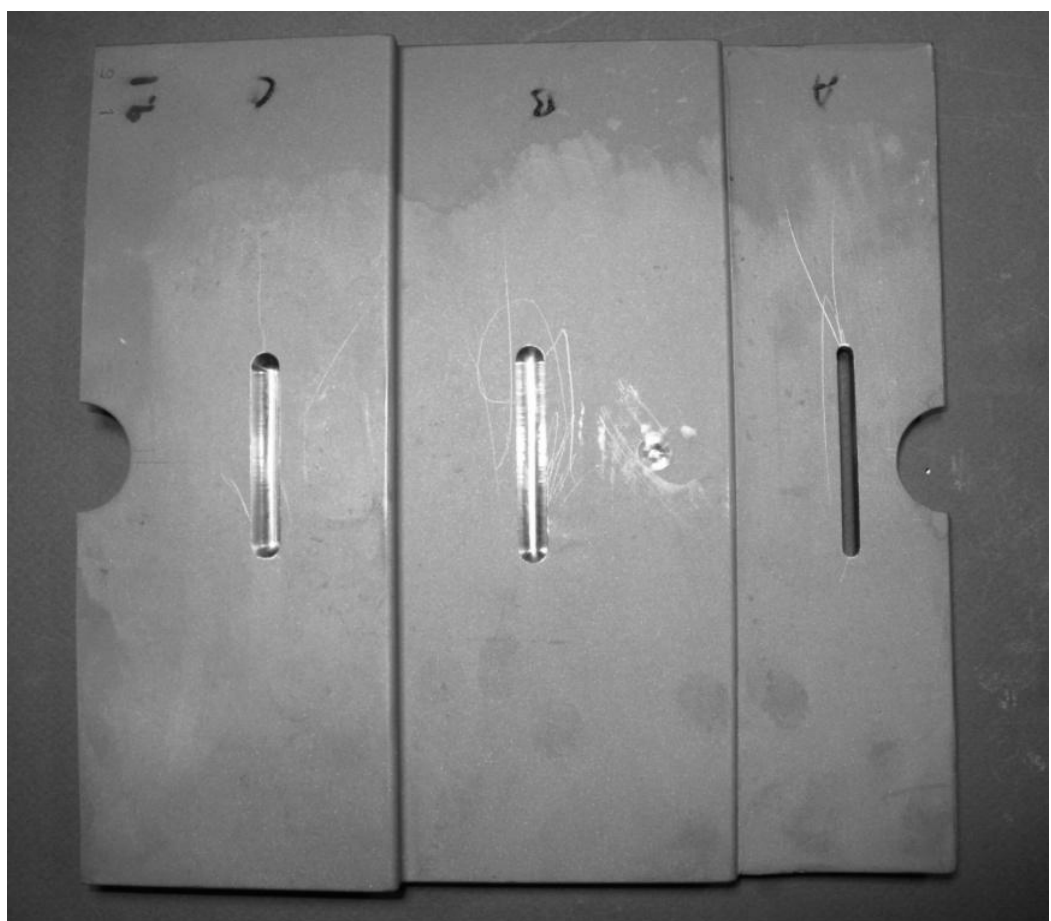

Figure 3. Staircase blank prepared with machined grooves for weld repair.

Four conditions were selected for evaluating the repair weldability: As cast, $1125^{\circ} \mathrm{C}-5 \mathrm{hrs}$, $1125^{\circ} \mathrm{C}-5 \mathrm{hrs}+1200^{\circ} \mathrm{C}-5 \mathrm{hrs}$ and $1200^{\circ} \mathrm{C}-5 \mathrm{hrs}$. After welding, fluorescent penetrant inspection and examination of metallographic sections of the welds were carried out. In total, fifteen cut-ups per stair case specimen were made. The total numbers of cracks were counted on the crosssections as a quantitative indicator of the weldability. 


\section{Results}

The as-cast microstructure, shown in Figure 4, reveals the typical dendritic pattern with primary and secondary dendrite arms together with eutectic constituents in the interdendritic regimes. EDS line scans across the Secondary Dendrite Arm Spacings (SDAS) show that Nb, Al and Ti accumulates in the inderdendritic regimes whereas $\mathrm{Co}, \mathrm{Cr}$ and $\mathrm{Fe}$ are enriched in the dendrite core as shown in Figure 5. The concentrations profiles are from the thick section and the length of the line scan is $1170 \mu \mathrm{m}$.

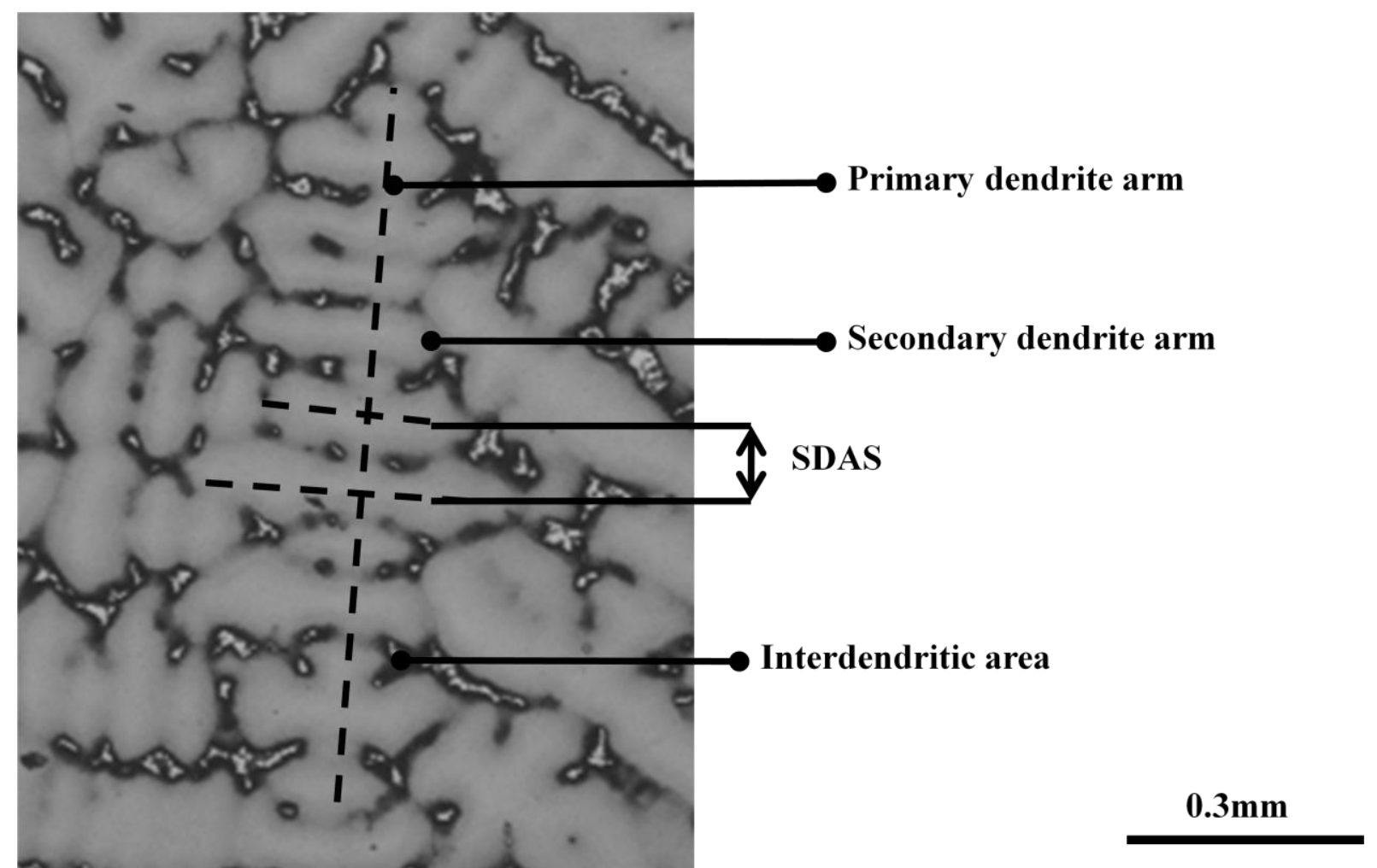

Figure 4. Typical dendiric pattern of the as cast microstructure of Allvac 718Plus.

$\mathrm{Nb}$ is the element of Allvac 718Plus which is most prone to segregation and therefore of key interest for a successful homogenization. 


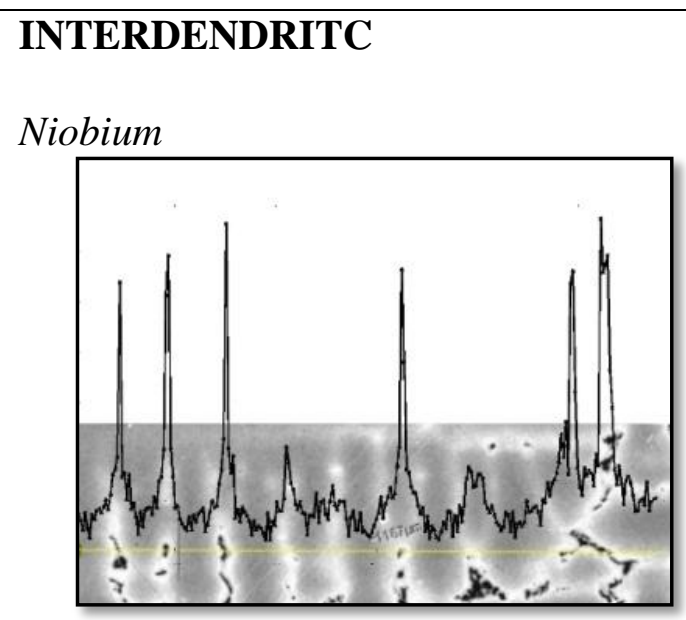

\section{Aluminium}

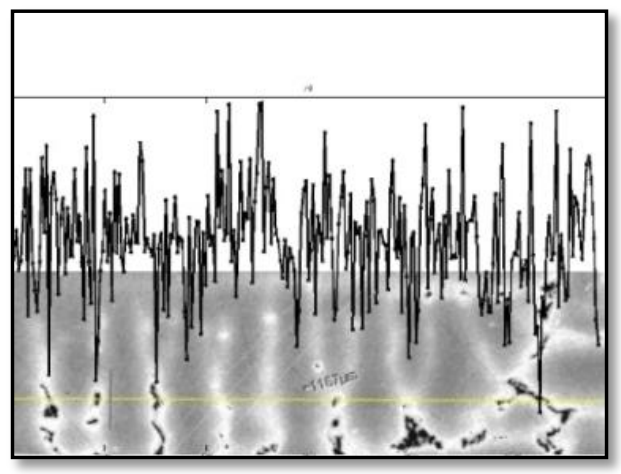

\section{Titanium}

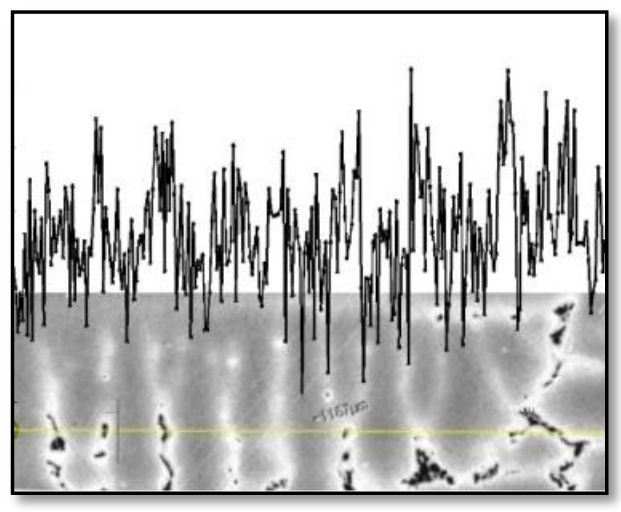

DENDRITIC

Cobalt

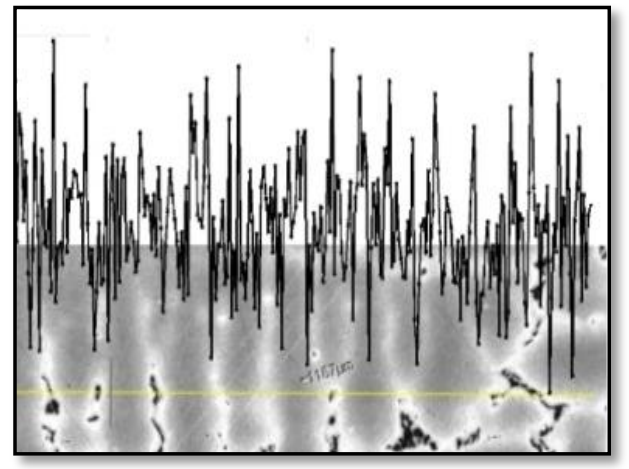

Chromium

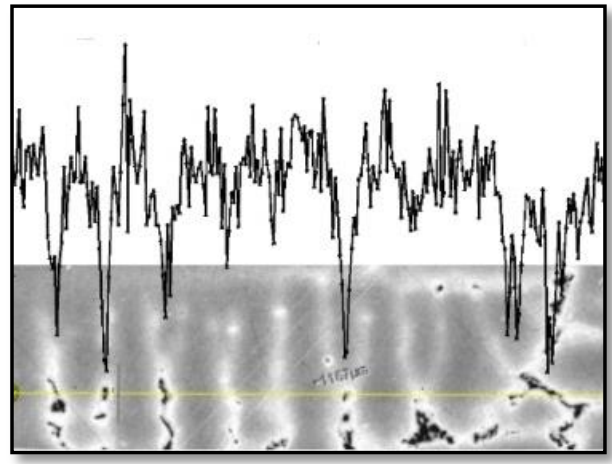

Iron

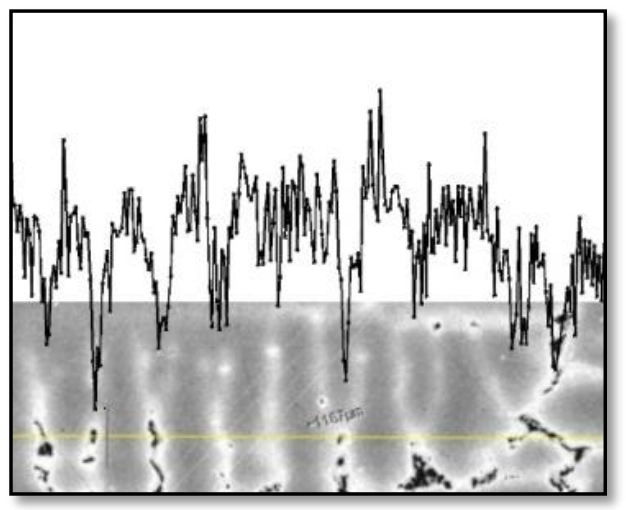

Figure 5. Segregation of elements across dendrites in the thick section in the as cast state.

The microstructure of the as-cast condition and its response to all the different homogenization heat treatments are shown in Figure 4 and 6, respectively. It is clearly seen that the eutectic constituents progressively disappear with increasing temperature and time. 


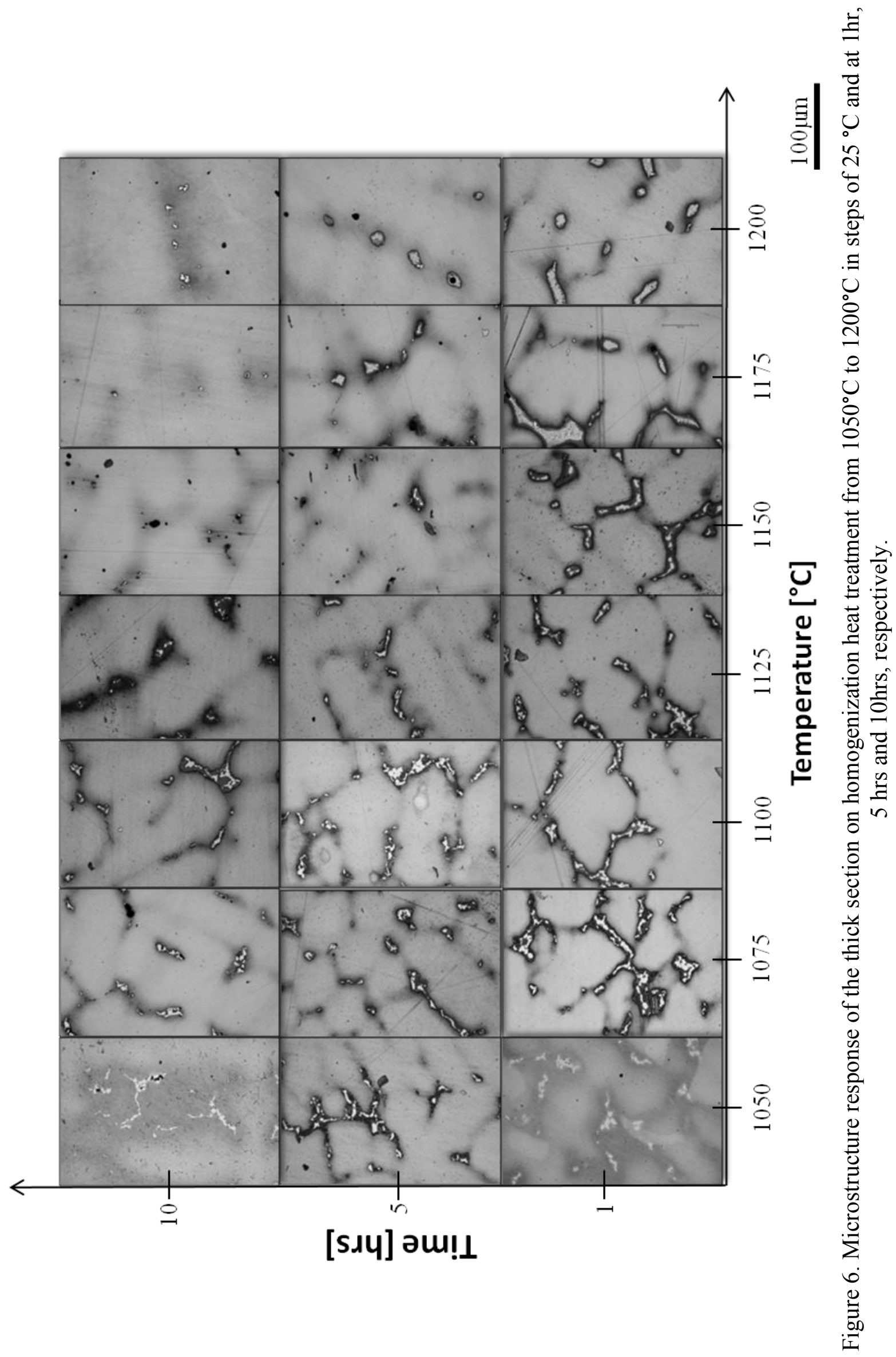


The results of the manual point count are summarized in Table 2. For the as-cast condition three different samples were examined, two un-aged and one aged, and the standard deviation was calculated for each section based on these three estimates. For both the thick and the intermediate section the standard deviation was found to be $\pm 0.2 \%$ whereas in the thin section it was considerable larger, $\pm 1.1 \%$.

Table 2. Manual point count result; mean of aged and un-aged samples, all sections.

\begin{tabular}{c|ccc|ccc|ccc}
\hline & \multicolumn{3}{|c|}{ Thick section } & \multicolumn{3}{|c|}{ Intermediate section } & \multicolumn{3}{|l}{ Thin section } \\
\hline As-cast & \multicolumn{3}{|c|}{$2.9 \%$} & & \multicolumn{3}{c|}{$1.5 \%$} & \multicolumn{3}{c}{$2.0 \%$} \\
\hline & $1 h r$ & $5 h r s$ & $10 h r s$ & $1 h r$ & $5 h r s$ & $10 h r s$ & $1 h r$ & $5 h r s$ & $10 h r s$ \\
\hline $1050^{\circ} \mathrm{C}$ & $2.8 \%$ & $3.1 \%$ & $3.0 \%$ & $3.2 \%$ & $3.0 \%$ & $3.4 \%$ & $2.4 \%$ & $1.8 \%$ & $1.7 \%$ \\
\hline $1075^{\circ} \mathrm{C}$ & $3.6 \%$ & $3.6 \%$ & $2.9 \%$ & $2.8 \%$ & $2.2 \%$ & $3.2 \%$ & $2.3 \%$ & $1.1 \%$ & $1.2 \%$ \\
\hline $1100^{\circ} \mathrm{C}$ & $2.6 \%$ & $1.9 \%$ & $1.9 \%$ & $2.1 \%$ & $2.2 \%$ & $1.2 \%$ & $2.1 \%$ & $1.9 \%$ & $1.2 \%$ \\
\hline $1125^{\circ} \mathrm{C}$ & $2.9 \%$ & $1.8 \%$ & $0.9 \%$ & $2.0 \%$ & $1.7 \%$ & $0.7 \%$ & $1.8 \%$ & $0.2 \%$ & $0.4 \%$ \\
\hline $1150^{\circ} \mathrm{C}$ & $1.9 \%$ & $1.2 \%$ & $0.6 \%$ & $1.6 \%$ & $0.6 \%$ & $0.4 \%$ & $0.9 \%$ & $2.5 \%$ & $0.2 \%$ \\
\hline $1175^{\circ} \mathrm{C}$ & $2.8 \%$ & $1.0 \%$ & $0.6 \%$ & $2.2 \%$ & $0.3 \%$ & $0.3 \%$ & $4.7 \%$ & $0.1 \%$ & $0.3 \%$ \\
\hline $1200^{\circ} \mathrm{C}$ & $4.1 \%$ & $1.5 \%$ & $0.2 \%$ & $3.0 \%$ & $0.2 \%$ & $0.1 \%$ & $1.1 \%$ & $0.3 \%$ & $0.1 \%$ \\
\hline
\end{tabular}

In the Table we also find values that deviate considerably from the general pattern among those for the thin section. Here we may pinpoint the value $4.7 \%$ for the $1175^{\circ} \mathrm{C}-1 \mathrm{hr}$ heat treatment and also the $2.5 \%$ for the $1150^{\circ} \mathrm{C}-5 \mathrm{hrs}$ heat treatment. The explanation for these anomalies may be understood when the segregation that occurs in the casting process is viewed on a larger scale as shown in Figure 7. Evidently eutectic liquid metal is accumulating in certain areas of the thin section during the casting process while not in the thicker ones, the reason for which we do not fully understand. This anomaly also accounts for the higher scatter of the point count in this thin section.
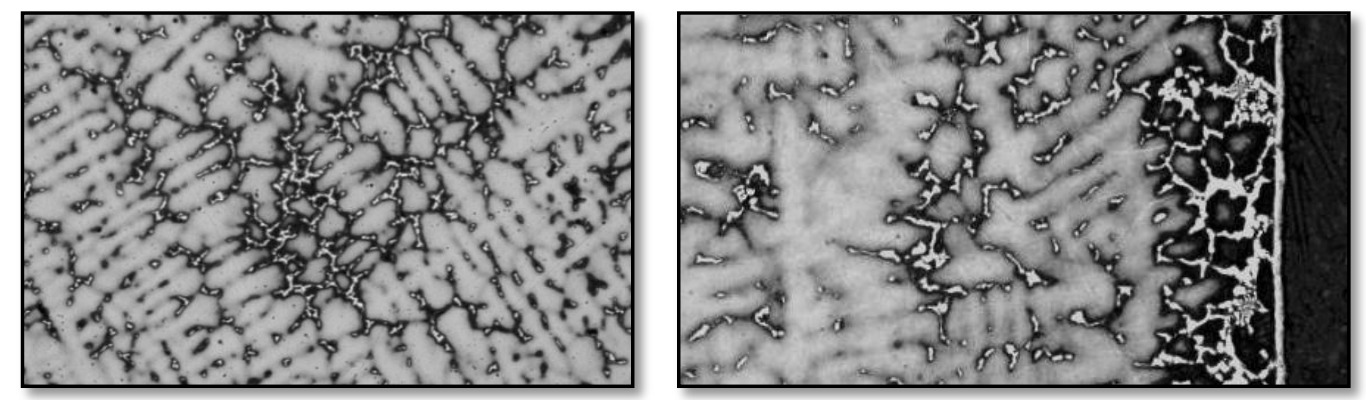

Figure 7. Regions where eutectic liquid metal has accumulated; found in the middle (left picture) and at the edge (right picture) of samples from the thin section.

The microstructures corresponding to the two anomalous values in the Table as mentioned above are shown in Figure 8. It goes without saying that if a sample is taken from an area with a high amount of eutectics as those shown in Figure 7 a very different microstructure could be expected in comparison with a test sample taken from an adjacent area with a small amount of eutectic. 

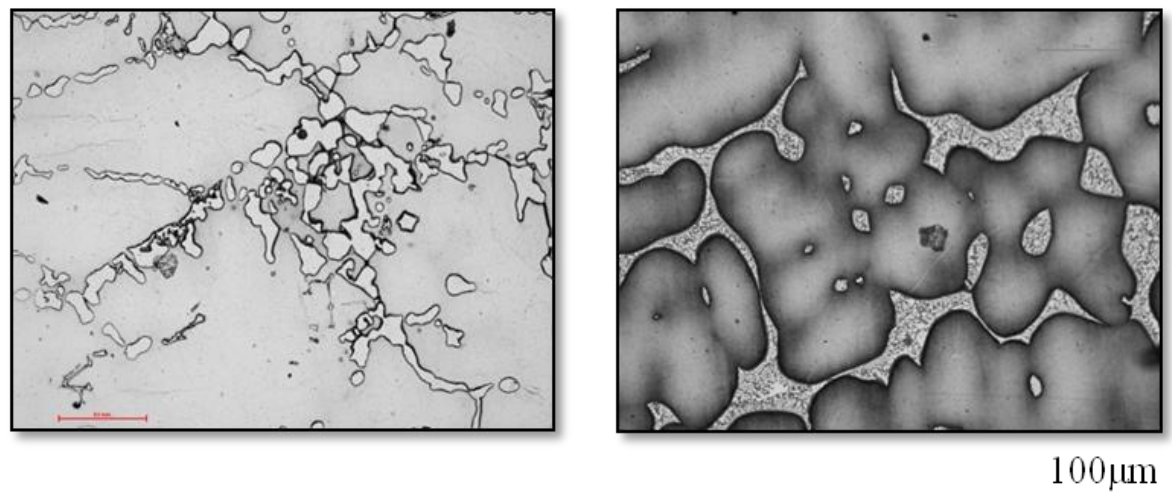

Figure 8. Deviating samples from the thin section. The left hand side picture belongs to the $1150^{\circ} \mathrm{C}-5 \mathrm{hrs}$ treatment whereas the right hand side belongs to $1175^{\circ} \mathrm{C}-1 \mathrm{hr}$.

Although the localized accumulation of eutectic is of large significance from a practical point of view it was considered essential to exclude the thin section from further analysis due to these observed anomalies in order to shed light on the general trends of homogenization. Thus, when plotting the amount of Laves phase against temperature for all three homogenization times it is seen how the first one-hour treatment does not efficiently reduce the Laves phase; there is even an increase at this short time for some measurements. However, as the time is increased to five or ten hours the Laves phase is significantly reduced as indicated in Figure 9.

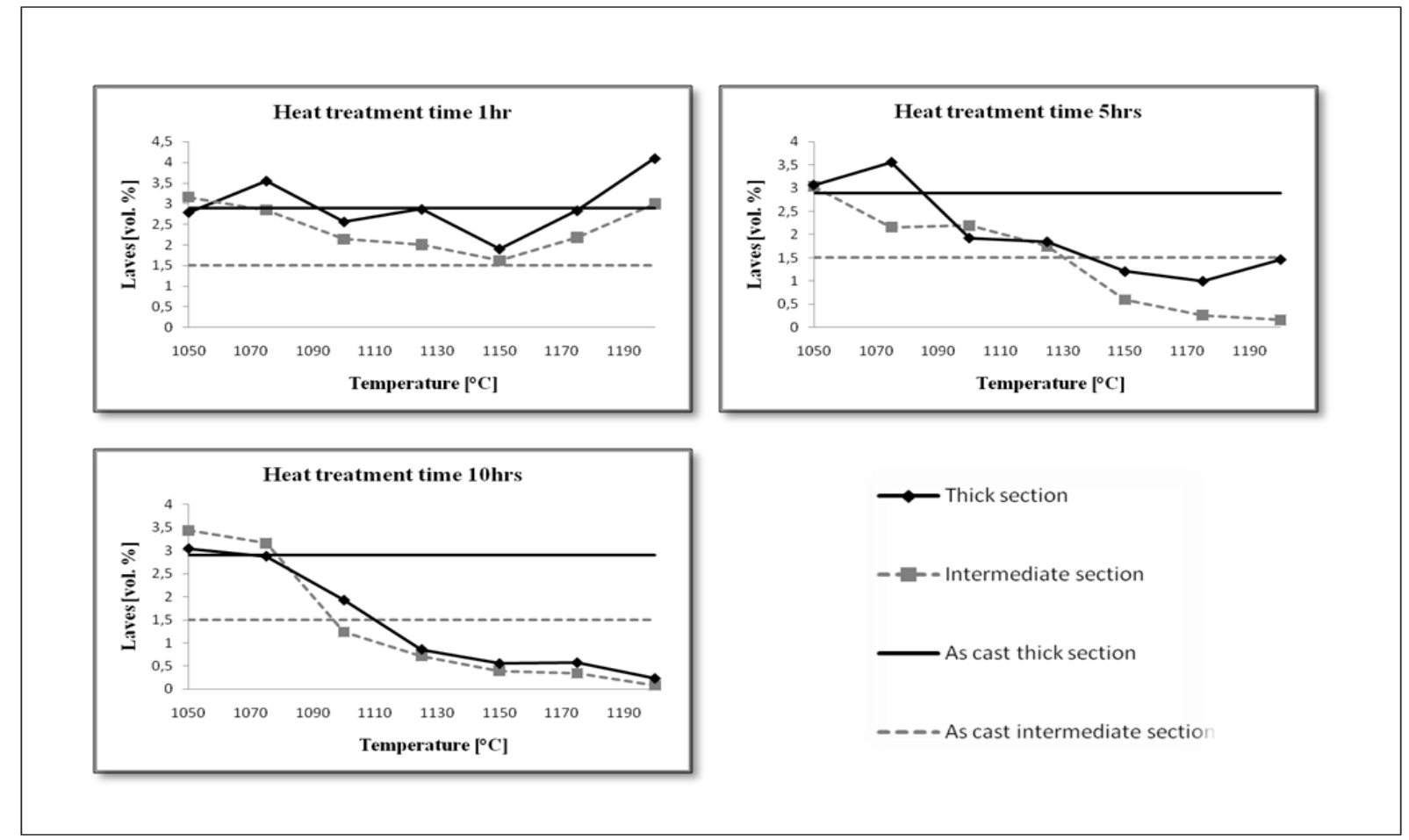

Figure 9. The amount of Laves phase versus temperature for the three different heat treatment times for the thick and intermediate sections in comparison. The upper horizontal lines represent the measured amounts of Laves phase for the thick section in the as-cast condition and the lower line the as cast condition for the intermediate section. 
At the two highest temperatures, $1175^{\circ} \mathrm{C}$ and $1200^{\circ} \mathrm{C}$, only vague traces of the dendritic patterns were possible to recognize on the etched surface after $10 \mathrm{hrs}$ of homogenization. By EDS analysis, however, the elemental segregation was still as high as $10 \mathrm{wt} \%$ for $\mathrm{Nb}$.

The macro hardness measurements, HV50, shown in Table 3 confirm the influence, although minor, of a finer structure on hardness. A significant increase of hardness $(15-20 \%)$ is evident for all homogenization heat treatments but with surprisingly small differences between the different ones.

Table 3. Macro hardness of aged material at different stages of homogenization

\begin{tabular}{c|c|c|c|c|c|c|c|c|c}
\hline & \multicolumn{3}{|c|}{ Thick section } & \multicolumn{3}{c|}{ Intermediate section } & \multicolumn{3}{c}{ Thin section } \\
\hline As-cast & \multicolumn{3}{|c|}{330} & \multicolumn{3}{c|}{344} & \multicolumn{3}{c}{347} \\
\hline & $1 \mathrm{hr}$ & $5 \mathrm{hrs}$ & $10 \mathrm{hrs}$ & $1 \mathrm{hr}$ & $5 \mathrm{hrs}$ & $10 \mathrm{hrs}$ & $1 \mathrm{hr}$ & $5 \mathrm{hrs}$ & $10 \mathrm{hrs}$ \\
\hline $1050^{\circ} \mathrm{C}$ & 374 & 381 & 384 & 395 & 388 & 395 & 403 & 412 & 399 \\
\hline $1075^{\circ} \mathrm{C}$ & 390 & 391 & 377 & 396 & 396 & 391 & 399 & 400 & 399 \\
\hline $1100^{\circ} \mathrm{C}$ & 388 & 392 & 400 & 398 & 391 & 400 & 404 & 386 & 410 \\
\hline $1125^{\circ} \mathrm{C}$ & 390 & 396 & 401 & 401 & 393 & 397 & 403 & 398 & 384 \\
\hline $1150^{\circ} \mathrm{C}$ & 393 & 391 & 401 & 388 & 395 & 397 & 402 & 406 & 396 \\
\hline $1175^{\circ} \mathrm{C}$ & 393 & 385 & 407 & 395 & 395 & 399 & 500 & 397 & 422 \\
\hline $1200^{\circ} \mathrm{C}$ & 396 & 396 & 393 & 393 & 391 & 389 & 400 & 414 & 383 \\
\hline
\end{tabular}

The result from repair welding can be seen in Figure 10. High temperature homogenization treatments evidently increase the susceptibility to cracking.

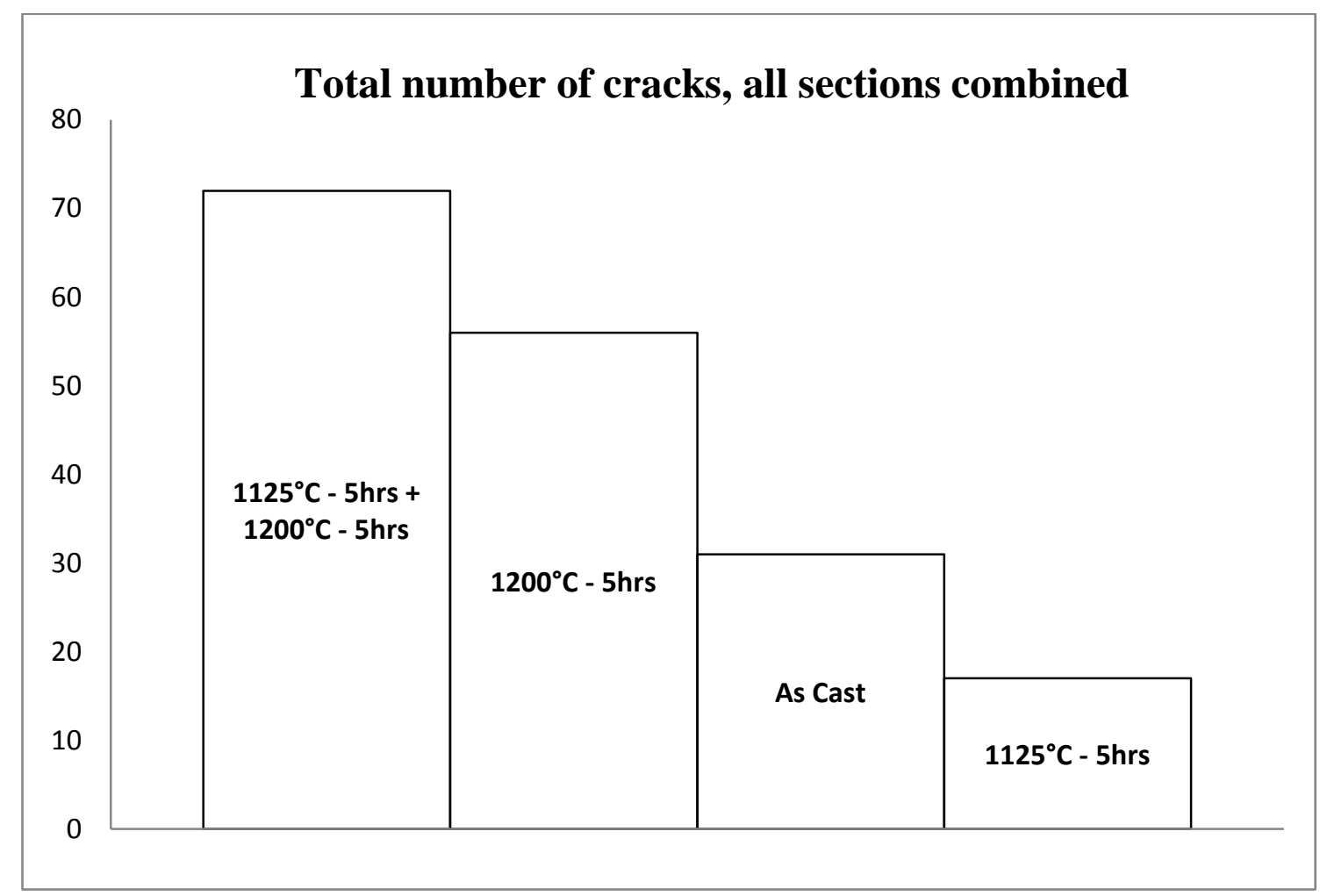

Figure 10. Total number of cracks in weld cross sections for different homogenization heat treatment conditions. 


\section{Discussion}

\section{Homogenization}

At the lower homogenization temperature regimes, below $1150^{\circ} \mathrm{C}$, and at the shortest time $1 \mathrm{hr}$, there is no or insignificant decrease in the Laves phase content as evident in Figure 9. The amount of Delta phase, however, decreases as temperature increases and the phase is completely dissolved at temperatures above $1125^{\circ} \mathrm{C}$ after 1 hour treatments, Figure 11.

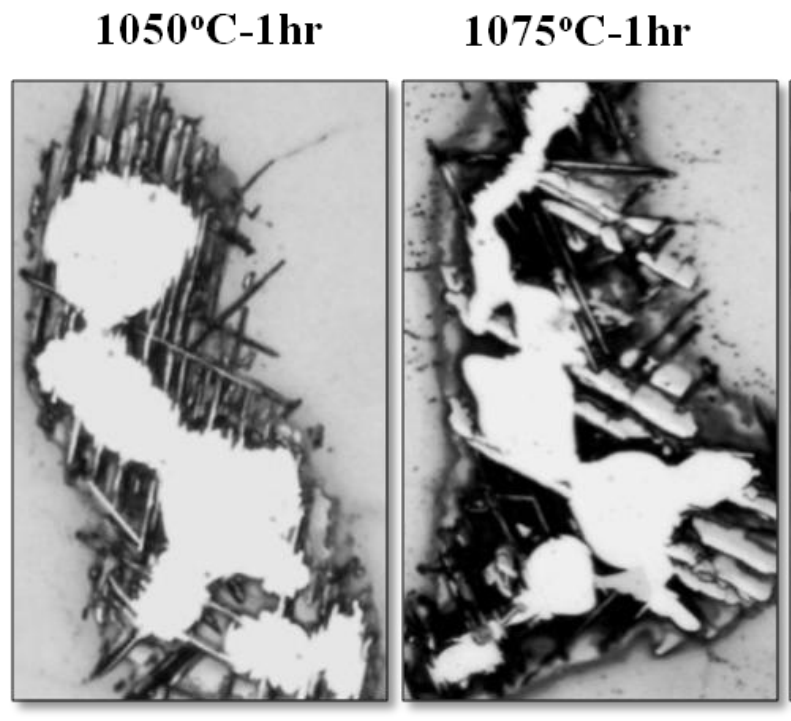

$1100^{\circ} \mathrm{C}-1 \mathrm{hr}$

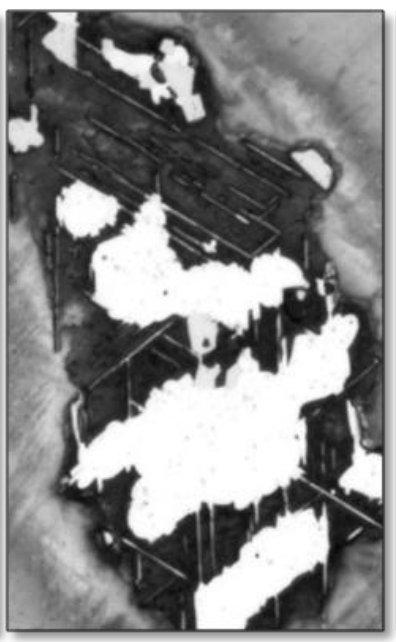

$1125^{\circ} \mathrm{C}-1 \mathrm{hr}$

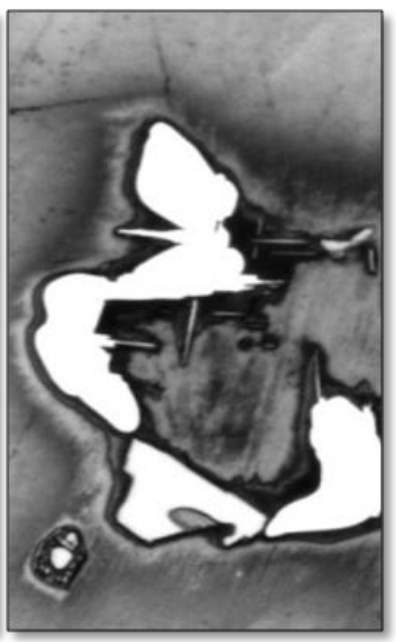

$10 \mu \mathrm{m}$

Figure 11. Evolution of Delta phase with temperature of the thick section.

The appearance of the Laves eutectic (Laves + the Gamma matrix phase) in the interdendritic areas is due to the segregation during solidification and are thus areas which are constitutionally unsTable. By nature of the large number of chemical elements in a superalloy of this kind, the equilibrium conditions in eutectic areas must however be complex. E.g., there is no distinct boundary between the Gamma matrix of the eutectic and the surrounding Gamma phase bulk matrix and there are numerous segregated elements involved which interact to change chemical potentials locally in a way little is known about.

The solution temperature of the Delta phase increases with the amount of $\mathrm{Nb}$ in the matrix but at the highest temperature most of the phase will still be dissolved including very close to the Laves phase. Since the whole eutectic area is unsTable the amount of Laves phase will be dissolved at high temperature given enough time as $\mathrm{Nb}$ diffuses away into the surrounding matrix as indicated in the right hand micrograph of Figure 11 but this trend is still more evident in micrographs in Figure 6 and the curves in Figure 9.

It can be noted in Figure 9 that the amount of Laves phase actually increases in the thick section of the material during the first hour of homogenization both in the lower temperature regimes as well as in the higher ones with an apparent minimum of this trend in between. In the intermediate section the same trend is even more pronounced although the amount of Laves phase is lower at the beginning in comparison with the thicker section. With longer dwell times, 5 and 10 hours 
respectively and at higher temperatures, the expected trend of reducing the amount of Laves phase is though observed. Still, at the lower temperatures and especially in the intermediate section the amount of Laves phase increases. Remarkably, given the large difference of the amount of Laves phase between the two thicknesses in the initial, as-cast, state, not only the shape of the curves are almost identical but the amount of the Laves phase immediately, in the specimens taken from the intermediate section, adjust to the same higher level as of the thick section and the curves then basically overlap.

As evident by the presence of the Delta phase adjacent to the Laves phase it may though be firmly assumed that the content of $\mathrm{Nb}$ is higher in this part of the matrix than that outside the actual eutectic area. If so, the following rational may be invoked to explain the anomalies observed.

As can be imagined and as already mentioned complex, dynamic phase equilibria may be assumed in eutectic areas and possibly uphill diffusion, as manifest by the increasing amount of Laves phase takes place. An evident explanation may however be the simple fact that when the Delta phase is dissolved at these temperatures the $\mathrm{Nb}$ content adjacent to the Laves interface increases at temperatures when the Laves phase is still locally sTable and thus benefits from this surplus of $\mathrm{Nb}$ by growing as shown in Figure 12. This of course assumes that Laves eutectic did not reach local equilibrium upon solidification.

The large difference between the initial amounts of Laves phase in the two sections may support this rational. Since, the solidification rate of the intermediate section can safely be assumed to be higher than in the thick section it may also be speculated that the proper local phase equilibrium within the eutectic area (Laves + Gamma matrix) did not developed to the same extent in the thinner material in comparison with the thicker one and thus with less than the equilibrium amount of Laves precipitated and consequently with a Gamma matrix locally oversaturated in $\mathrm{Nb}$ manifested by a comparatively large amount of Delta phase which later precipitated due to this fact. Upon heating to homogenization temperatures the local equilibrium conditions of Laves eutectic area is restored (the amount of Laves phase finding its local equilibrium value) within a short period of time and quicker in the thinner section which is logical. At the same time, some of the excess Delta phase must be dissolved in this process which is also what is observed; especially the thinner platelets dissolve which again is logical. It is however difficult to quantify the amount of Delta phase due to its plate morphology. The increase of the amount of Laves phase during the initial state of homogenization heat treatments is still surprising and certainly merits further and deeper studies. Still, the above explanation may fully account for the anomalies observed in this study. 


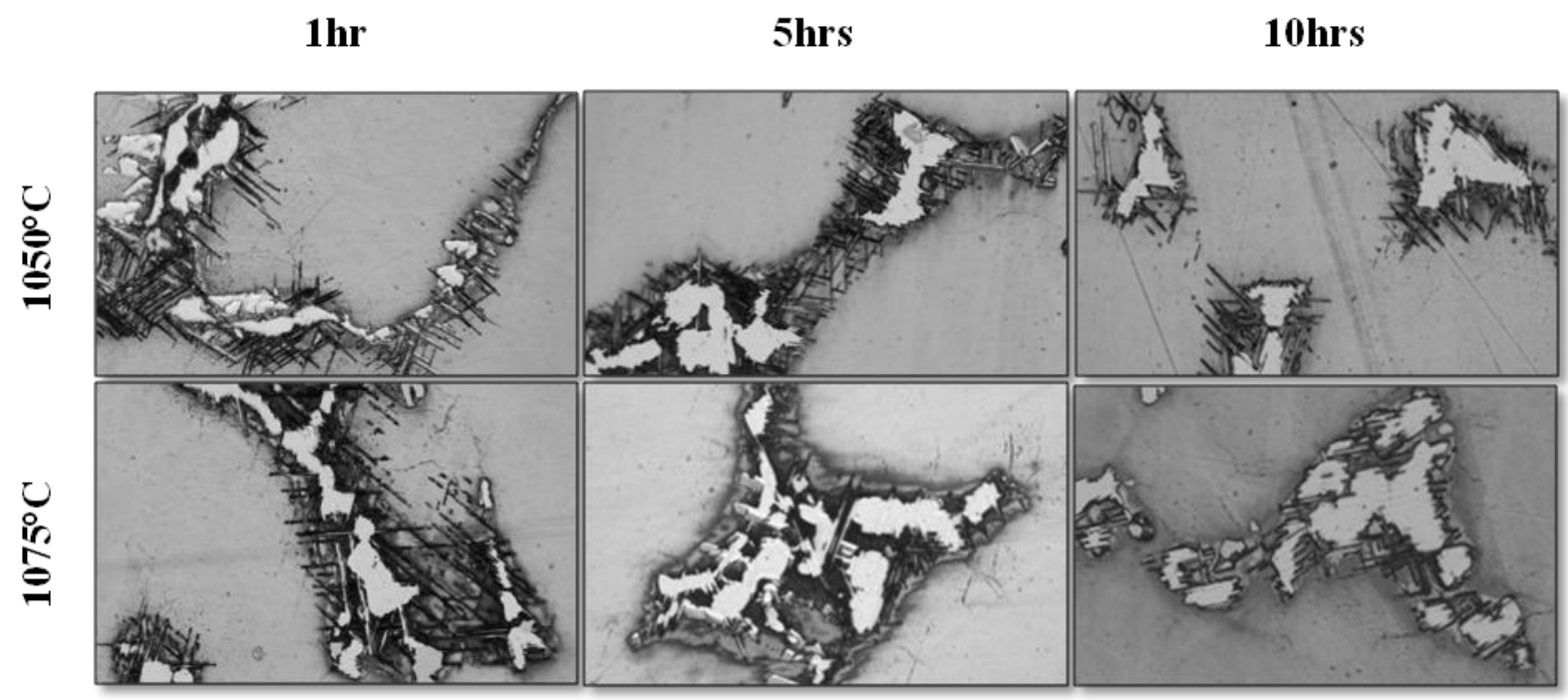

Figure 12. Evolution of needle-phase upon heat treatment of the thick section.

When looking at the micro-structural evolution of the material it can be seen that the amount of Laves is generally lower for the samples where no lamellar phase is present and this indicates that homogenization of the Laves will not take place to any larger extent at lower temperatures as long as the lamellar phase is surrounding the Laves. The first process suggested to take place upon heat treatment is therefore coarsening and dissolution of the lamellar phase. As the homogenization heat treatment temperature is raised above $1175^{\circ} \mathrm{C}$ the Laves phase is melted and drains the grain boundary, Figure 13. At short times (1hr) at high temperatures (1175$1200^{\circ} \mathrm{C}$ ) the Laves phase melts but will not have time to dissolve completely whereas resolidification will take place which can be seen in the micro-graphs in Figure 13.

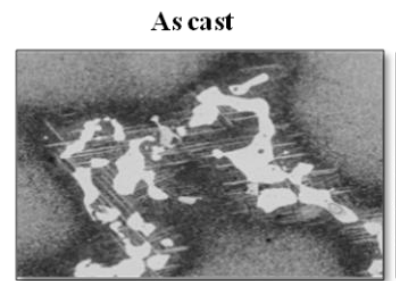

$1125^{\circ} \mathrm{C}-1 \mathrm{hr}$

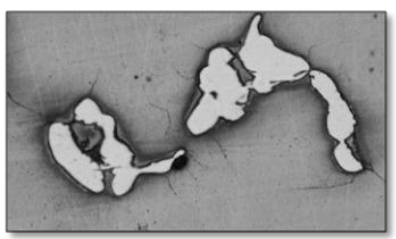

$1050^{\circ} \mathrm{C}-1 \mathrm{hr}$

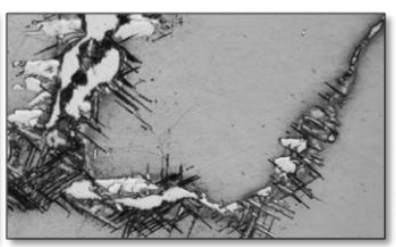

$1150^{\circ} \mathrm{C}-1 \mathrm{hr}$

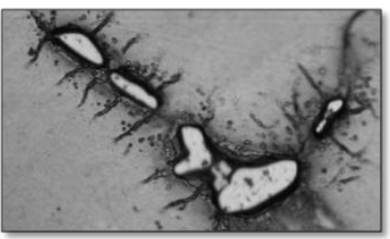

$1075^{\circ} \mathrm{C}-1 \mathrm{hr}$

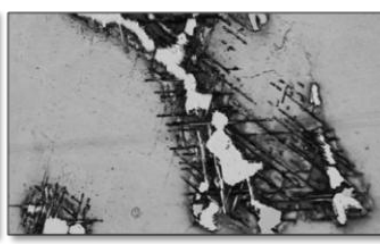

$1175^{\circ} \mathrm{C}-1 \mathrm{hr}$

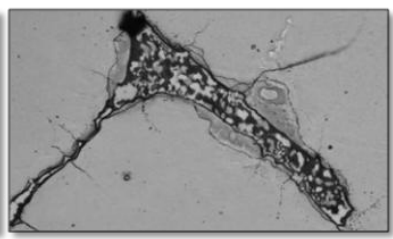

$1100^{\circ} \mathrm{C}-1 \mathrm{hr}$

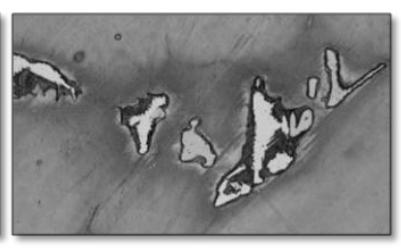

$1200^{\circ} \mathrm{C}-1 \mathrm{hr}$

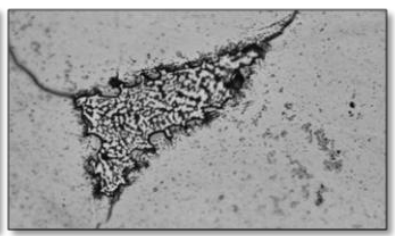

$50 \mu \mathrm{m}$

Figure 13. Laves and Delta phase appearance for $1 \mathrm{hr}$ homogenization treatments at different temperatures - note liquation (and re-solidification) of Laves eutectic areas at $1175^{\circ} \mathrm{C}$ and above.

It is reasonable to believe that the solution of Laves takes place long before any long range homogenization of niobium will occur across dendrites, a belief that may also explain the absence of hardness variation between different homogenization heat treatments. 
Our observations and discussion on the effect of different homogenization heat treatments may be summarized as follows:

1. Depending on actual solidification rates the Laves eutectic (Laves phase + Gamma matrix) will not reach equilibrium in the segregated areas between the dendrites.

2. The Gamma matrix of the Laves eutectic will be oversaturated in $\mathrm{Nb}$.

3. Excess $\mathrm{Nb}$ in the Gamma matrix will precipitate as Delta phase platelets on cooling

4. Upon first stages of homogenization the Laves eutectic will reach equilibrium through partial dissolution of Delta phase and growth of the Laves phase.

\section{Welding}

Observations made in the welding part of this study revealed that contrary to common belief, the highest degree of homogenization was the condition which is most susceptible to cracking during welding as evident from the bar chart in Figure 10. An intermediate homogenization heat treatment, $1125^{\circ} \mathrm{C}-5 \mathrm{hrs}$, produced the best results but not much better than the material in the ascast condition.

Generally it is considered that the presence of eutectic phases deteriorates weldability [3]. In the present study this was found to be far from true since the most prominent eutectic phase, the Laves eutectic, is not present in the most homogenized material.

Homogenization at temperatures above the Laves eutectic melting temperature (Figure 13) is very effective in redistributing the $\mathrm{Nb}$ possibly by wetting the grain boundaries as the transport mechanism. If so, a grain boundary embrittlement may occur of which the nature is poorly understood. This, of course, may contribute to the cracking susceptibility. However, eutectic phases are not always considered deleterious since the liquid produced can actually heal cracks initially created by back filling [6].

\section{Conclusions}

- At the lowest homogenization temperatures $\left(1050^{\circ} \mathrm{C}\right.$ and $\left.1075^{\circ} \mathrm{C}\right)$ no dissolution of the Laves phase occurred even after $10 \mathrm{hrs}$ dwell time.

- The amount of Laves Phase increased at the initial stages of homogenization at the lowest temperatures and especially for the finer structure of the intermediate section.

- Heat treatments at $1175^{\circ} \mathrm{C}$ and above will result in melting of the Laves eutectics and faster dissolution of the Laves phase.

- No long-range homogenization across dendrites was observed.

- Macro Vickers hardness measurements reveal a rapid increase in hardness upon first stages of homogenization but no further increase with time and temperature was noted. 
- Surprisingly the most homogenized material $1125^{\circ} \mathrm{C}-5 \mathrm{hrs}+1200^{\circ} \mathrm{C}-5 \mathrm{hrs}$ was the condition most susceptible to weld cracking and considerably more susceptible than the material in the as-cast condition.

\section{Acknowledgements}

Morgan Pettersson, Mikael Karlsson, Patrik Karlsson, Stefan Frödin, Lars Eriksson at the welding department are greatly acknowledged for their help with repair weld operation. We also thank Per Göthe at the department of Machining, Inspection \& Automation and Pia Olsson at the department of Surface Treatment for helping out with the macro etching of 718Plus stair case test plates.

The work presented in this paper is partly financed by VITAL, which is a new collaborative research project, running for four years, which aims to significantly reduce aircraft engine noise and $\mathrm{CO}_{2}$ emissions. Snecma leads a consortium of 53 partners gathering all major European engine manufacturers: Rolls-Royce Plc, MTU Aero Engines, Avio, Volvo Aero, Techspace Aero, Rolls-Royce Deutschland and ITP, and the airframer Airbus. The work in this paper has been performed under WP 4.4 Advanced Hot Structures/4.4.5 Evaluation of Alternative Alloy with Temperature Capability over IN 718, where Volvo Aero specifically contributed to the work presented here.

\section{References}

1. C.T. Sims, N.S. Stoloff and W.C. Hagel, Superalloys II- High Temperature Materials for Aerospace and Industrial Power, (New York, NY: John Wiley \& Sons Inc., 1987).

2. G. Sjöberg, J. Andersson, A. Sjunnesson, "New Materials in the Design and Manufacturing of Hot Structures for Aircraft Engines - ALLVAC 718PLUS”, ISABE-2009-1286 (2009).

3. J. Andersson, G. Sjöberg, L. Viskari, A. Brederholm, H. Hänninen and C. S. Knee, "Hot Cracking of Allvac 718Plus, Alloy 718 and Waspaloy at Varestraint testing", Proceedings of the $47^{\text {th }}$ Conference of Metallurgists (2008), pp. $401-413$.

4. W. D. Cao and R. L. Kennedy, "Recommendations for Heat Treating Allvac $\AA 718$ Plus ${ }^{\circledR}$ Alloy Parts", ATI Allvac (www.allvac.com/718Plus), Feb. 24 (2006).

5. R.G. Thompson, J.J. Cassimus, D.E. Mayo and J.R. Dobbs, "The Relationship between Grain Size and Microfissuring in Alloy 718”, Welding Journal, Apr. (1985), pp. 91-96.

6. J. Andersson, G. Sjöberg and H. Hänninen, "Metallurgical Response of Electron Beam Welded Allvac 718Plus" (Paper presented at the $3^{\text {rd }}$ International Hot Cracking Workshop, Columbus, Ohio, 16 March 2010). 